\title{
Magnesium Removal from an Aluminum A-332 Molten Alloy Using Enriched Zeolite with Nanoparticles of $\mathrm{SiO}_{2}$
}

\author{
R. Muñoz-Arroyo, ${ }^{1}$ H. M. Hdz-García, ${ }^{1}$ J. C. Escobedo-Bocardo, ${ }^{2}$ E. E. Granda-Gutierrez, \\ J. L. Acevedo-Dávila, ${ }^{1}$ J. A. Aguilar-Martínez, ${ }^{3}$ and A. Garza-Gomez ${ }^{1}$ \\ ${ }^{1}$ COMIMSA-Saltillo, Ciencia y Tecnología No. 790, Colonia Saltillo 400, 25290 Saltillo, COAH, Mexico \\ ${ }^{2}$ CINVESTAV Unidad Saltillo, Avenida Industria Metalúrgica 1062, Parque Industrial Saltillo-Ramos Arizpe, \\ 25900 Ramos Arizpe, COAH, Mexico \\ ${ }^{3}$ CIIIA-FIME-UANL, Carretera a Salinas Victoria km 2.3, 66600 Apodaca, NL, Mexico
}

Correspondence should be addressed to R. Muñoz-Arroyo; rita.munoz@comimsa.com

Received 30 July 2014; Revised 6 December 2014; Accepted 7 December 2014; Published 24 December 2014

Academic Editor: Haiming Lu

Copyright (C) 2014 R. Muñoz-Arroyo et al. This is an open access article distributed under the Creative Commons Attribution License, which permits unrestricted use, distribution, and reproduction in any medium, provided the original work is properly cited.

In order to improve the $\mathrm{Mg}$ removal from an $\mathrm{A}-380$ molten alloy, mixtures of zeolite and $\mathrm{SiO}_{2}$ nanoparticles $\left(\mathrm{SiO}_{2(\mathrm{NPs})}\right)$ were tested. Zeolite was enriched with 2.5, 5, 7.5, 10, or $12.5 \mathrm{wt}-\%$ of amorphous $\mathrm{SiO}_{2(\mathrm{NPs})}$. The $\mathrm{SiO}_{2(\mathrm{NPs})}$ and zeolite were mixed for $30 \mathrm{~min}$ in ethanol for each experiment and then dried in a furnace at $80^{\circ} \mathrm{C}$ for $12 \mathrm{~h}$. The enriched zeolites were analyzed by scanning electron microscopy, transmission electron microscopy, and $\mathrm{N}_{2}$ gas adsorption analysis. The $\mathrm{Mg}$ removal was carried out injecting each mixture into the molten aluminum alloy at $750^{\circ} \mathrm{C}$ using argon. The $\mathrm{Mg}$ content of the molten alloy was measured after different periods of the injection time. Zeolites enriched with 2.5 and $5 \mathrm{wt}-\%$ of $\mathrm{SiO}_{2(\mathrm{NPs})}$ were demonstrated to be the better mixtures, removing $\mathrm{Mg}$ from an initial content of 1.6 to a final content of 0.0002 and $0.0101 \mathrm{wt}-\%$, respectively, in 45 min of injection.

\section{Introduction}

Al-Si alloy is one of the aluminum casting alloys widely used in automotive industries due to its excellent microstructure, casting, and mechanical characteristics as is the A380 alloy. Abedi et al. [1] showed that magnesium can refine the size of primary $\alpha(\mathrm{Al})$ phase and eutectic silicon. Vončina et al. [2] established the grain refining influence by Ce in A380 alloy. On the other hand, the increase of ultimate tensile strength and elongation in A380 alloy can be obtained by SDAS (secondary dendrite arm spacing) values ranging from 5.70 to $10 \mu \mathrm{m}$ on the squeeze cast parts as shown by Murat Lus [3]. But it is noticeable that in the case of the A380 alloy for automotive use, the standard indicates a maximum of $0.1 \mathrm{wt}-\%$ of $\mathrm{Mg}$ because the presence of this element in the alloy increases its oxidation tendency [4]. However, when the alloy is produced from scrap, the resultant $\mathrm{Mg}$ content of the alloy is higher than $0.1 \mathrm{wt}-\%$ and the excess of Mg needs to be removed. Vieira et al. [5] used the chlorine method and discuss bubble-formation theories and magnesium kinetic removal from aluminum scraps using chlorine and inert gas fluxing. In spite of that Neff and Cochran [6] showed that the kinetics of the magnesium removal as $\mathrm{MgCl}_{2}$ is rapid, but the unreacted chlorine and the gaseous coproduct $\mathrm{AlCl}_{3}$ can limit the environmental acceptability of the process. Electrochemical method and the incorporation of powder reagents (fluorides) are used for $\mathrm{Mg}$ removal [7]. Both have disadvantage: the first is not profitable because of the high cost of electricity and the second produces toxic wastes. As can be seen, the secondary aluminum industry has been focused on the development of processes that overcome the mentioned limitations. One option is represented by the use of purified silica-based powders because the generated products in the treatment are not pollutants. Reports on 
literature establish the effect of $\mathrm{SiO}_{2}$ on the $\mathrm{Mg}$ removal as presented by Muñoz et al. [8] and Escobedo et al. [9], which is performed according to the following:

$$
\begin{gathered}
\mathrm{Mg}_{(\mathrm{l})}+2 \mathrm{Al}_{(\mathrm{l})}+2 \mathrm{SiO}_{2(\mathrm{~s})} \longrightarrow \mathrm{MgAl}_{2} \mathrm{O}_{4(\text { spinel })}+2 \mathrm{Si}_{(\mathrm{s})} \\
\Delta G_{750^{\circ} \mathrm{C}}^{\circ}=-377.09 \mathrm{~kJ} .
\end{gathered}
$$

However, silica requires supplementary processes for its concentration resulting in additional costs. Additionally, the kinetics of the $\mathrm{Mg}$ removal using silica is relatively slow [10]. However, in recent studies Muñoz et al. [8, 11] have demonstrated the feasibility of $\mathrm{Mg}$ removal from aluminum molten alloys by injecting zeolite (containing more than $50 \mathrm{wt}-\%$ of $\mathrm{SiO}_{2}$ ) and silica using an inert carrier gas. On the other hand, nanotechnology has been applied in foundry processes to improve mechanical properties of some materials according to studies in $\mathrm{Al}$ alloy treatment with nano-SiC powders in order to improve toughness [12]. $\mathrm{Li}$ et al. [13] improved the tensile strength and toughness as well as wear resistance with the addition of $\mathrm{SiC}$ nanopowders in the performance of traditional cast iron. Therefore, the nanotechnology may be used for removing undesirable elements during the adjustment of the final chemical alloys composition. Zeolite, with its high porosity, is ideal to be impregnated with amorphous $\mathrm{SiO}_{2 \text { (NP's) }}$. Further, amorphous $\mathrm{SiO}_{2 \text { (NP's) }}$ can act as chemical catalyst to remove magnesium of molten aluminum improving the efficiency of the process. Due to the fact that the surface structural defects (i.e., undercoordinated units) strongly increase with decreasing nanoparticle size, diffusion of atomic species to the surface of nanoparticles significantly increases as suggested by Huynh et al. [14] and Carmona-Muñoz et al. [15]. Therefore, such considerations are appropriate for impregnating the porous inner part of zeolite. It is noteworthy that the nanoparticles can increase the surface area of zeolite to reduce the time of magnesium removal from molten aluminum alloys.

The aim of this work was the study of the Mg removal from a molten aluminum alloy by using mixtures of zeolite and amorphous $\mathrm{SiO}_{2(\mathrm{NPs})}$ as $\mathrm{Mg}$ remover agents. The capacity of $\mathrm{Mg}$ agents was evaluated by comparing its effect with that corresponding to the pure zeolite.

\section{Experimental Procedure}

2.1. Raw Materials and Characterization of Zeolites without Amorphous $\mathrm{SiO}_{2(N P s)}$. The mineral zeolite was crushed in a ball mill and classified obtaining powders with an average particle size smaller than $150 \mu \mathrm{m}$. The chemical composition of the minerals was determined by atomic absorption spectroscopy, inductively coupled plasma atomic emission spectroscopy, and gravimetric method. Amorphous $\mathrm{SiO}_{2}$ (NPs) (Aldrich, 99.99\%) with size smaller than $10 \mathrm{~nm}$ were selected for this work. These nanoparticles were characterized by TEM.

2.2. Impregnation and Characterization of Zeolites with Amorphous $\mathrm{SiO}_{2(N P s)}$. The impregnation of zeolite with amorphous $\mathrm{SiO}_{2}$ (NPs) was reached mixing the selected amount of nanoparticles $(2.5,5,7.5,10$, or $12.5 \mathrm{wt}$-\%) with zeolite for $30 \mathrm{~min}$ in ethanol and drying the mixture in a furnace at $80^{\circ} \mathrm{C}$ for $12 \mathrm{~h}$. Samples of the enriched zeolites were analyzed by TEM and SEM and their surface area was measured by Autosorb 1-C using liquid nitrogen adsorption.

2.3. Selection of the Al Alloy and Mg Removal by Injection. The selected alloy was the A-332 aluminum base alloy (Al11.64Si-0.338Fe-2.05Cu-1.6Mg-1.54Ni). An induction electric furnace, equipped with a silicon carbide crucible of $12 \mathrm{~kg}$ of capacity and temperature control, was used to melt and hold the alloy. Injection equipment, with devices to measure and control the gas and powder flows, was used to introduce the powder mixtures into the melt. The injection lance (internal diameter of $6.98 \mathrm{~mm}$ ) was made of graphite and covered externally with refractory material. The selected parameters for the submerged powder injection experiments were argon (ultrahigh purity) flow of $4.4 \mathrm{~L} / \mathrm{min}$, powder flow of $16.2 \mathrm{~g} / \mathrm{min}$, mass of aluminum alloy of $8 \mathrm{~kg}$, and aluminum alloy treatment temperature of $750^{\circ} \mathrm{C}$. The lance was submerged at the $85 \%$ of the depth of the melt. The variable in the experiments was the composition of the powder mixtures zeolite- $\mathrm{SiO}_{2(\mathrm{NPs})}$ to be injected $(0,2.5,5$, $7.5,10$, or $12.5 \mathrm{wt}-\%$ of $\left.\mathrm{SiO}_{2(\mathrm{NPs})}\right)$. The mass of the powders to be injected was calculated considering the $\mathrm{SiO}_{2}$ as the solid reagent and spinel and silicon as products according to the chemical reaction (1). For each experiment, samples of the melt were obtained every $10 \mathrm{~min}$ and the produced dross (oxidized material) was collected at the end of the experiment. The solidified samples were analyzed by spark atomic emission spectrometry to determine their chemical compositions and a sample of the dross was analyzed by XRD. Finally, the quantity of dross was weighted and the efficiency of process was calculated with

$$
\eta(\%)=\frac{M g_{(\text {start })}-M g_{(\text {end })}}{M g_{(\text {start })}} * 100
$$

where $\eta(\%)$ is efficiency, $\mathrm{Mg}_{\text {(start) }}$ is initial $\mathrm{Mg}$ content (wt-\%), and $\mathrm{Mg}_{(\mathrm{end})}$ is final $\mathrm{Mg}$ content (wt- $\%$ ).

2.4. Characterization of Reaction Products by DRX and SEM of Samples after the Magnesium Removal by Injection. In order to determine the reaction products of slags formed during the injection of enriched zeolite with different percentages of $\mathrm{SiO}_{2(\mathrm{NPs})}$, the samples were characterized by X-ray diffraction (XRD). In the case of semireacted particles founded in the metallic samples, these samples were characterized and analyzed by SEM and EDX, respectively.

\section{Results and Discussions}

3.1. Raw Materials Characterization. Figure 1(a) shows a SEM image of a particle of pure zeolite (irregular morphology). Two zones can be observed: (1) a clear zone (labeled LZ) corresponding to the Carlsbad twins and (2) a dark zone (labeled DZ) containing mainly $\mathrm{Si}$ and $\mathrm{O}$ and $\mathrm{Al}, \mathrm{Ca}, \mathrm{Na}$, and $\mathrm{K}$ traces (classical chemical composition of Feldspar's group). 


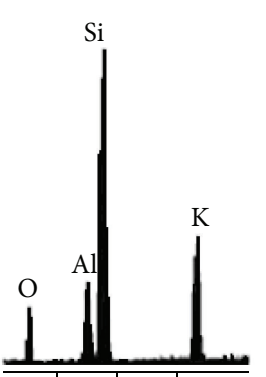

$1.00 \quad 2.003 .00$

LZ

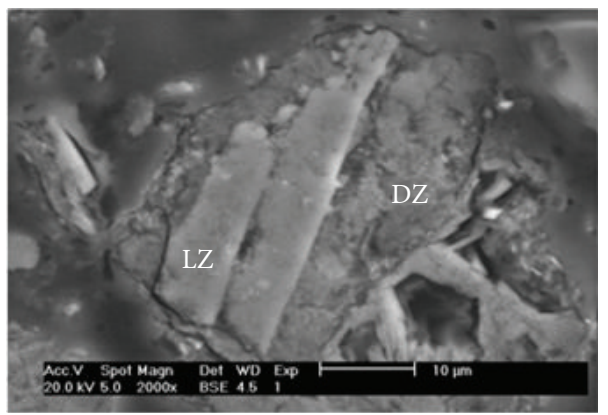

200N 50 2000x BSE 45 i

(1)

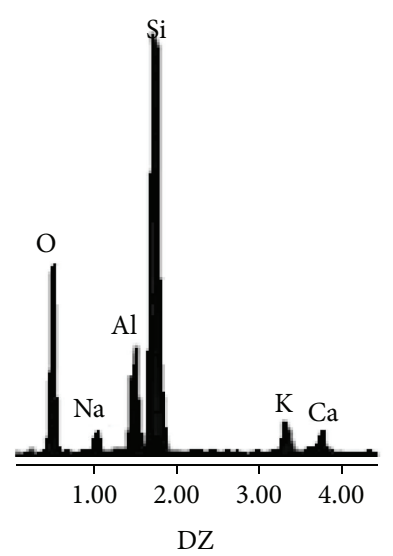

(a)

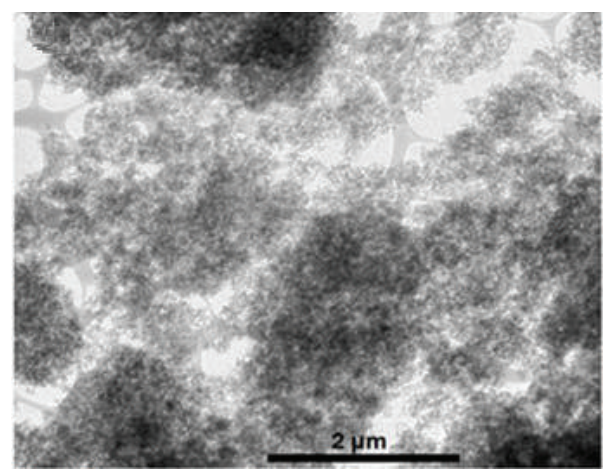

(b)

FIgURE 1: (a) SEM image of pure zeolite with Carlsbad twins and (b) TEM image of amorphous $\mathrm{SiO}_{2(\mathrm{NPs})}$ as received.

TABLE 1: Compounds identified by XRD.

\begin{tabular}{lc}
\hline Compound & Chemical formula \\
\hline Heulandite & $\mathrm{Ca}\left(\mathrm{Si}_{7} \mathrm{Al}_{2}\right) \mathrm{O}_{18} \cdot 6 \mathrm{H}_{2} \mathrm{O}$ \\
Sanidine & $\mathrm{KAlSi}_{3} \mathrm{O}_{8}$ \\
\hline
\end{tabular}

Table 1 shows the compounds identified in zeolite by XRD. Figure 1(b) shows a TEM image of pure nanoparticles. It is possible to observe agglomerates of nanoparticles of spherical morphologies. These nanoparticle characteristics allow high chemical reactivity because this kind of surfaces has a high specific surface energy.

\subsection{Characterization of the Enriched Zeolites with Amor-} phous $\mathrm{SiO}_{2(N P s)}$. A sample of enriched zeolite (12.5 wt-\% of $\mathrm{SiO}_{2(\mathrm{NPs})}$ ) was analyzed by SEM. Figures 2(a) and 2(b) show backscattered electron SEM images of the scanned area at high magnifications. Small agglomerates of less than $1 \mu \mathrm{m}$ (Figure 2(b)) can be appreciated. Due to the size of the scanning spot, it is not appropriate to perform chemical analysis by EDX.

Examining other zones of the same sample, agglomerated particles of spherical morphology were observed (Figure 3). This fact can be due to the effects of sonication by ultrasound. The EDS analysis of the surface of the agglomerate shows that

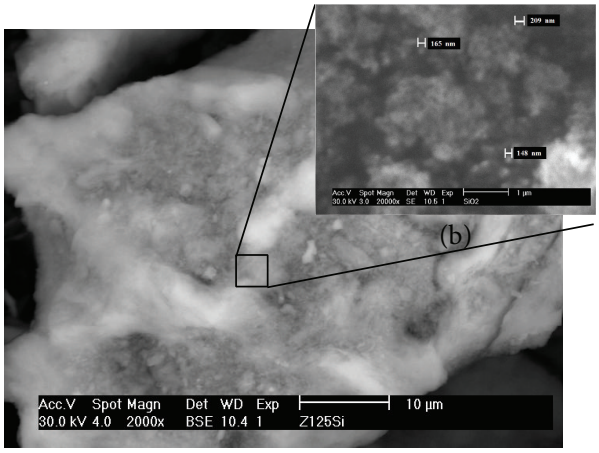

(a)

FIGURE 2: SEM images of (a) zeolite with $12.5 \%$ of $\mathrm{SiO}_{2(\mathrm{NPs})}$ and (b) $\mathrm{SiO}_{2(\mathrm{NPs})}$ agglomerates at high amplifications.

its chemical composition approaches $\mathrm{SiO}_{2}$. The advantage of such spherical morphology is that it increases the reaction kinetics due to its high surface energy.

Representative samples of enriched zeolite (2.5 and 12.5 wt- $\%$ of $\mathrm{SiO}_{2(\mathrm{NPs})}$ ) were analyzed by TEM. Studies such as that by Tomokazu and Hidekazu [16] suggest that by decreasing the silicoaluminate particle size $(<300 \mu \mathrm{m})$, the rate of $\mathrm{Mg}$ removal decreases. However, this disadvantage can be avoided with the impregnation of $\mathrm{SiO}_{2(\mathrm{NPs})}$ on the 

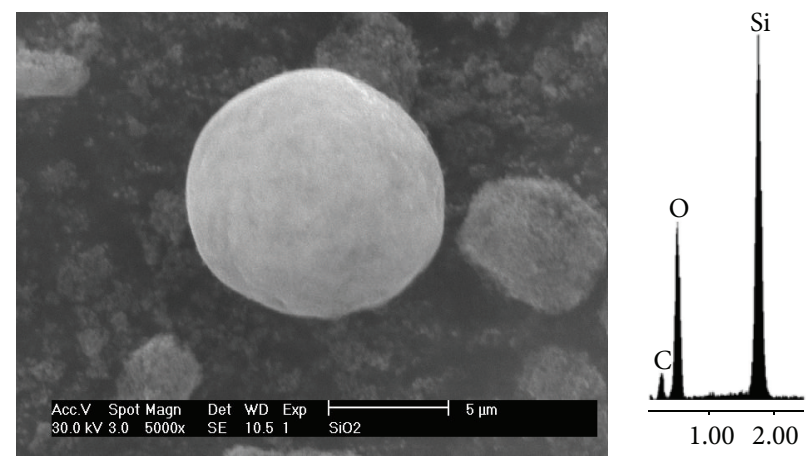

FIGURE 3: Secondary electron SEM image of a spherical particle rich in $\mathrm{SiO}_{2(\mathrm{NPs})}$.

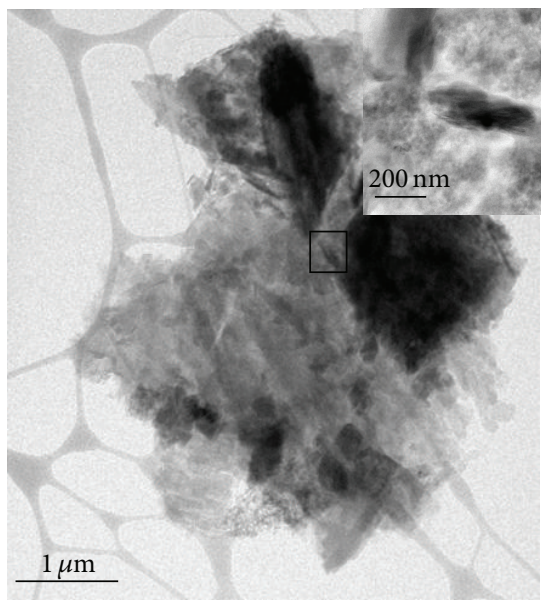

(a)

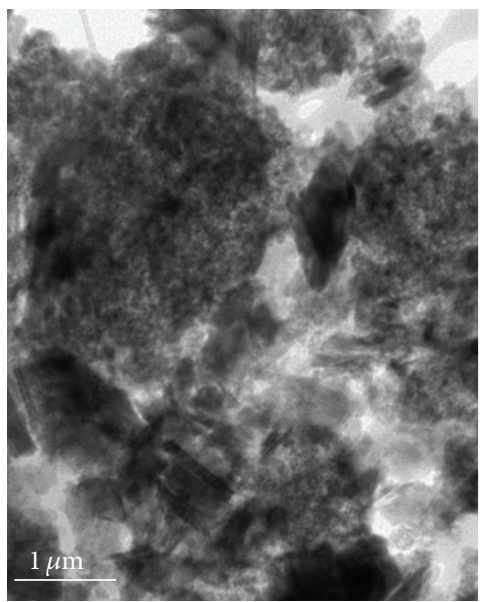

(b)

FIgURE 4: TEM images of enriched zeolites with $\mathrm{SiO}_{2(\mathrm{NPs})}$ : (a) $2.5 \%$ and (b) $12.5 \%$.

surface of the zeolite, changing in this way the surface area of the material. At high amplification, it is observed that the $\mathrm{SiO}_{2(\mathrm{NPs})}$ are immersed in a stretch gap approach to $1 \mu \mathrm{m}$ between zeolitic materials (dark zone) (Figure 4(a)). By contrast, the enriched zeolite with $12.5 \%$ of $\mathrm{SiO}_{2(\mathrm{NPs})}$ shows a high quantity of agglomerated nanoparticles (Figure 4(b)). Both surface aspects can affect the rate and time of $\mathrm{Mg}$ removal by injection.

The characterization of zeolite without and with 2.5, 5, $7.5,10$, and $12.5 \%$ of $\mathrm{SiO}_{2(\mathrm{NPs})}$ by Autosorb yielded important information that is necessary for understanding the role between the pores of zeolite and the $\mathrm{SiO}_{2(\mathrm{NPs})}$. As it can be seen in Table 2, the zeolite shows a pore size of $15 \mathrm{~nm}$ that is sufficient to get inside the $\mathrm{SiO}_{2(\mathrm{NPs})}$. These pores can be filled and enriched with nanoparticles with a size smaller than $15 \mathrm{~nm}$. Likewise, the amorphous nature of nanoparticles can increase the rate of magnesium removal before a spinel shell is formed on the surface of zeolite. As a consequence, the zeolite acts as nanostructured transport medium. On the other hand, according to Table 2, the values of the surface area suggest the following aspects: in the zeolite with 2.5 to $5 \%$ of $\mathrm{SiO}_{2(\mathrm{NPs})}$ the nanoparticles are being introduced inside the pores and among spaces of the mineral, leading to a decrease in the surface area. However, in the case of enriched zeolite with $7.5,10$, and $12.5 \%$ of $\mathrm{SiO}_{2(\mathrm{NPs})}$ the surface area increases. It means that the nanoparticles are agglomerated on the surface of zeolite because the pores are full of them. This is the reason of a higher amount of dross in the molten aluminum with 7.5, 10 , and $12.5 \%$ of $\mathrm{SiO}_{2(\mathrm{NPs})}$ in comparison with that of the 2.5 and $5 \%$.

3.3. Magnesium Removal by Injection of Zeolite without and with $\mathrm{SiO}_{2(N P s)}$. Figure 5 shows the reduction of the $\mathrm{Mg}$ content in the alloy as a function of the injection time. As it is seen in this figure when pure zeolite (without $\mathrm{SiO}_{2(\mathrm{NPs})}$ ) is injected, the final content of $\mathrm{Mg}$ in the alloy, after $70 \mathrm{~min}$ of injection, is $0.7 \mathrm{wt}-\%$ of $\mathrm{Mg}$. The best result was obtained when zeolite $+2.5 \% \mathrm{SiO}_{2(\mathrm{NPs})}$ was injected. In this case, the $\mathrm{Mg}$ content in the alloy was $0.1 \mathrm{wt}-\%$ after only $47 \mathrm{~min}$ of injection, which is in agreement with the standard, and the final $\mathrm{Mg}$ content, after $70 \mathrm{~min}$ of injection, reaches $0.0002 \mathrm{wt}-$ $\%$. Similar effects occur when zeolite $+5 \% \mathrm{SiO}_{2(\mathrm{NPs})}$ is used (52 min of injection to reach $0.1 \mathrm{wt}-\%$ of $\mathrm{Mg}$ ). By contrast, the $\mathrm{Mg}$ removal decreases when zeolite enriched with 7.5 to $12.5 \%$ of $\mathrm{SiO}_{2(\mathrm{NPs})}$ is used. In these cases, the target of $0.1 \mathrm{wt}-\%$ of $\mathrm{Mg}$ is not reached, even by injection for $70 \mathrm{~min}$. 
TABLE 2: Measurements of surface area of zeolite without and with amorphous $\mathrm{SiO}_{2(\mathrm{NPs})}$.

\begin{tabular}{|c|c|c|c|c|c|}
\hline Material & $\mathrm{Mg}_{\text {(end) }}(\mathrm{wt}-\%)$ & $W_{\text {(oxidized material) }}(\mathrm{kg})$ & $\eta(\%)$ & Area surface $\left(\mathrm{m}^{2} / \mathrm{g}\right)$ & Pore size $(\mathrm{nm})$ \\
\hline Zeolite & 0.5007 & 1.210 & 68.75 & 22.09 & 15 \\
\hline Zeolite: $2.5 \% \mathrm{SiO}_{2(\mathrm{NPs})}$ & 0.0002 & 0.058 & 99.98 & 20.98 & 12 \\
\hline Zeolite: $5 \% \mathrm{SiO}_{2(\mathrm{NPs})}$ & 0.0101 & 1.100 & 99.25 & 18.47 & 13 \\
\hline Zeolite: $7.5 \% \mathrm{SiO}_{2(\mathrm{NPs})}$ & 0.0500 & 1.130 & 98.37 & 21.88 & 14.5 \\
\hline Zeolite: $10 \% \mathrm{SiO}_{2(\mathrm{NPs})}$ & 0.1040 & 1.600 & 96.87 & 22.94 & 17 \\
\hline Zeolite: $12.5 \% \mathrm{SiO}_{2(\mathrm{NPs})}$ & 0.1090 & 1.860 & 93.18 & 25.98 & 19.5 \\
\hline
\end{tabular}

$\mathrm{Mg}_{(\mathrm{end})}$ : final $\mathrm{Mg}$ content in the alloy.

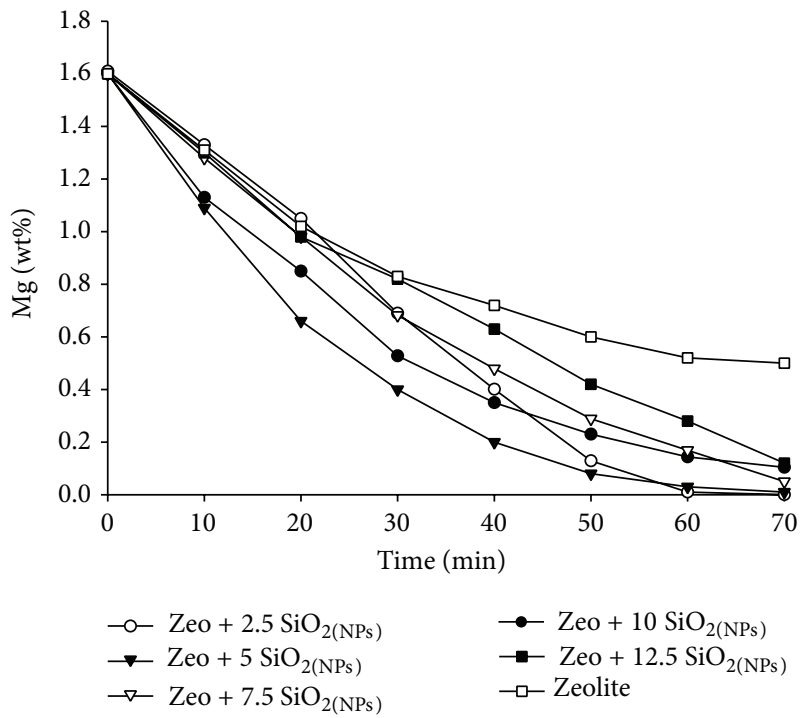

FIgURE 5: Mg removal from the alloy as a function of injection time using zeolite and zeolite with different percentages of $\mathrm{SiO}_{2(\mathrm{NPs})}$.

Comparatively, the $\mathrm{SiO}_{2(\mathrm{NPs})}$ enriched zeolite increases the efficiency of the chemical reaction to remove $\mathrm{Mg}$ due to the size and amorphous nature of the $\mathrm{SiO}_{2(\mathrm{NPs})}$. This suggests that the nanoparticles improve the surface energy of the zeolite and its amorphous nature becomes as chemical catalyst. It should be noted that the initial content of $\mathrm{Mg}$ in this research work is considerably high $(1.6 \mathrm{wt}-\% \mathrm{Mg})$ with regard to that in other reports in the literature $[4,10]$ that starts from $1 \mathrm{wt}-$ $\%$ of $\mathrm{Mg}$ using enriched zeolites with different percentages of $\mathrm{SiO}_{2}$ as bulk. Likewise, removal times over $60 \mathrm{~min}$ in order to reach $0.1 \mathrm{wt}-\%$ of $\mathrm{Mg}$ in the alloy are as shown by MuñozArroyo et al. [11]. This means that the Mg removal method using nanoparticles improves the efficiency of the process and decreases the removal time. Besides, the power consumption can be lower in the process of $\mathrm{Mg}$ removal.

3.4. Characterization of Reaction Products during the Magnesium Removal by Injection. The slags were analyzed by $\mathrm{X}$-ray diffraction in order to found the products of the reaction between the enriched zeolite with $\mathrm{SiO}_{2(\mathrm{NPs})}$ and the elements of the molten bath (Figure 6). The XRD patterns of the slags show peaks corresponding to spinel, clinoptilolite, periclase, anorthite, and so forth. Elements such as aluminum

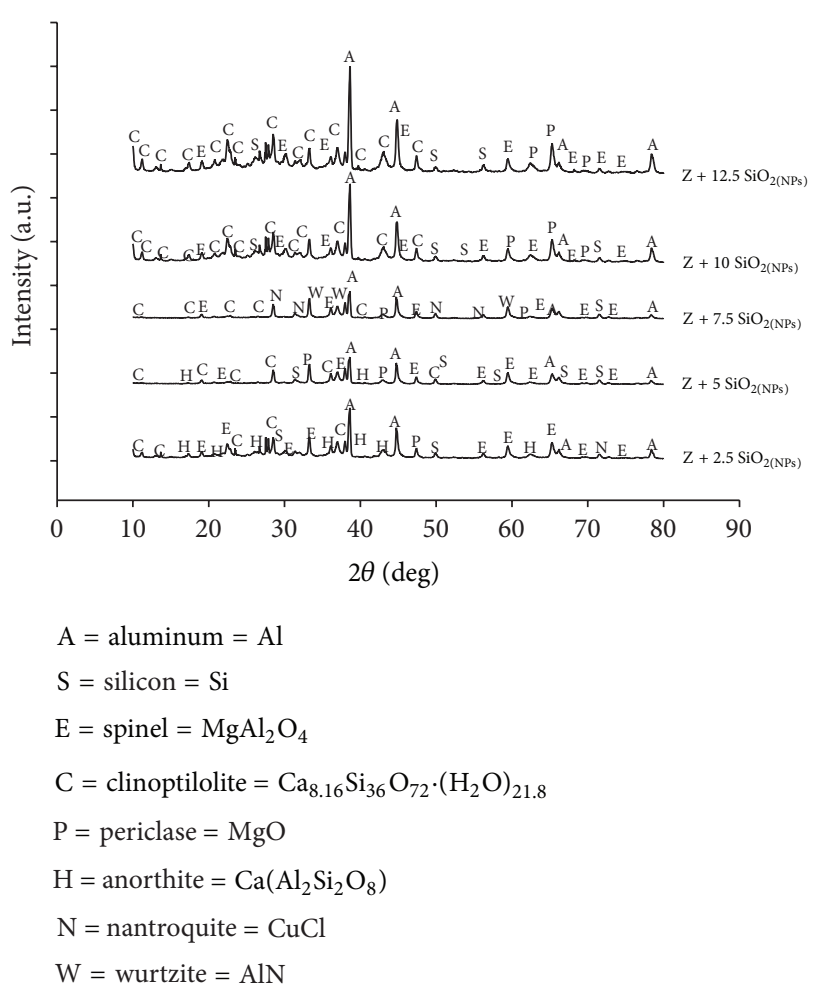

FIGURE 6: X-ray diffraction patterns of slags from the process where zeolite is with nanoparticles of $\mathrm{SiO}_{2}$.

and silicon were also detected and belong to the aluminum alloy. It is noticeable that in the slag from the zeolite with $7.5 \% \mathrm{SiO}_{2(\mathrm{NPs})}$ were identified wurtzite and nantroquite. It is postulated that both compounds are formed from impurities of the base magnesium alloy that was used to adjust the content of magnesium in the Al-Si alloy.

The metallic specimens obtained during injection were analyzed by scanning electron microscopy to understand the kinetics of the magnesium removal. As can be seen, in Figure $7($ a), a particular specimen that shows a semireacted particle of zeolite obtained in the samples treated with enriched zeolite with 5\% nanoparticles injected for $20 \mathrm{~min}$ was found. According to the corresponding EDX spectra, the chemical composition of the shell is approaching the stoichiometry of spinel. Meanwhile, the center of the particle belongs to the chemical compositions of zeolite, as shown in Figures $7(\mathrm{~b})$ and $7(\mathrm{c})$. During the magnesium removal, the 


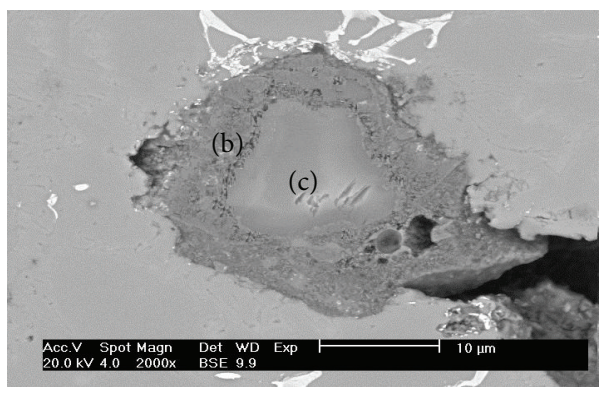

(a)

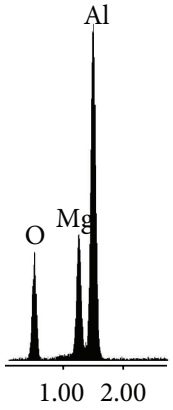

(b)

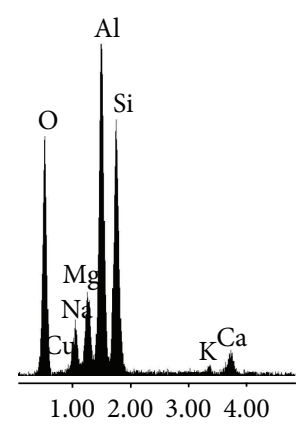

(c)

FIGURE 7: (a) Image of backscattered electron for a semireacted particle of enriched zeolite with $5 \%$ of $\mathrm{SiO}_{2}$ nanoparticles, obtained after 20 minutes of injection; EDX of (b) shell and (c) center of particle.

reaction products form a shell on the surface of enriched zeolite with $\mathrm{SiO}_{2(\mathrm{NPs})}$. Hence, the reaction rate is slow due to the nature of the process; a shell of reaction products is formed on the particles and makes the mass transfer difficult.

On this viewpoint, it is postulated that the formation of a stable shell on the surface will be quickly formed as a stable diffusive barrier among dissolved $\mathrm{Mg}$ in the liquid bath of aluminum and shell on the zeolite (spinel) that reduces the removal kinetics. Finally, when nanoparticles are in contact among them, they tend to reduce their free energy reducing their surface energy. Then, at high temperature inside the molten bath, the nanoparticles coalesce (sintering of the nanoparticles) reducing substantially the reaction area. This is the reason why the efficiency of magnesium removal decreases and a higher amount of dross in the molten aluminum with $7.5,10$, and $12.5 \%$ of $\mathrm{SiO}_{2(\mathrm{NPs})}$ is formed.

\section{Conclusions}

The use of mineral zeolite enriched with $2.5 \mathrm{wt}-\%$ of $\mathrm{SiO}_{2(\mathrm{NPs})}$ provided higher $\mathrm{Mg}$ removal from the molten alloy than that obtained using pure zeolite. The kinetics of magnesium removal decreases as the percentage of $\mathrm{SiO}_{2(\mathrm{NPs})}$ increases, promoting the formation of a dross rich in intermetallic compounds.

The density, high surface area, and feasibility of ion exchange of the enriched particles allow better powder-liquid contact improving the process kinetics.

The methodology presented in this study is feasible to be applied on an industrial scale.

\section{Conflict of Interests}

The authors declare that there is no conflict of interests regarding the publication of this paper.

\section{Acknowledgment}

The authors wish to express their gratitude to the National Council of Science and Technology (CONACyT) for supporting the development of the postdoctoral fellow of R. MuñozArroyo.

\section{References}

[1] A. Abedi, M. Shahmiri, B. A. Esgandari, and B. Nami, "Microstructural evolution during partial remelting of Al-Si alloys containing different amounts of magnesium," Journal of Materials Science \& Technology, vol. 29, no. 10, pp. 971-978, 2013.

[2] M. Vončina, P. Mrvar, M. Petrič, and J. Medved, "Microstructure and grain refining performance of Ce on A380 alloy," Journal of Mining and Metallurgy, Section B: Metallurgy, vol. 48, no. 2, pp. 265-272, 2012.

[3] H. Murat Lus, "Effect of casting parameters on the microstructure and mechanical properties of squeeze cast A380 aluminum die cast alloy, Kovove Materialy, vol. 50, no. 4, pp. 243-250, 2012.

[4] Y. Wang, H.-T. Li, and Z. Fan, "Oxidation of aluminium alloy melts and inoculation by oxide particles," Transactions of the Indian Institute of Metals, vol. 65, no. 6, pp. 653-661, 2012.

[5] E. A. Vieira, J. R. De Oliveira, G. F. Alves, D. C. R. Espinosa, and J. A. S. Tenório, "Use of chlorine to remove magnesium from molten aluminum," Materials Transactions, vol. 53, no. 3, pp. 477-482, 2012.

[6] V. D. Neff and P. B. Cochran, "Panel of Aluminum Processing," Light Metals, USA, vol. 1993, pp. 1053-1060, 1993.

[7] T. Lehner, P. J. Koros, and V. Ramachandran, International Symposium on Injection in Process Metallurgy, vol. 1-2, The Minerals, Metals \& Materials Society, Warrendale, Pa, USA, 1991.

[8] R. Muñoz, J. C. Escobedo, H. M. Hernández et al., "Magnesium removal from molten aluminum alloys using zeolite and zeolitesilica mixtures," Archives of Metallurgy and Materials Science, vol. 53, pp. 965-968, 2008.

[9] J. C. Escobedo, J. F. Hernández, S. Escobedo et al., "Estudio cinético de la eliminación de magnesio en las aleaciones de aluminio mediante la inyección de polvos de sílice," Revista de Metalurgia, vol. 39, no. 3, pp. 172-182, 2003.

[10] J. C. Escobedo, A. Flores, V. J. F. Hernández et al., "Removal of magnesium aluminum alloys using the method of reagent injection powders," in Light Metals, pp. 885-891, TSM, 2003.

[11] R. Muñoz-Arroyo, J. C. Escobedo-Bocardo, H. M. HernándezGarcía et al., "Estudio del mecanismo de eliminación de magnesio de aleaciones Al-Si en estado líquido mediante inyección de minerales base sílice," Revista de Metalurgia, vol. 46, no. 4, pp. 1988-4222, 2010.

[12] M.-L. Chen, L. Kang, J. Yang, L. Yang, and H. Gao, "Microstructure and mechanical properties of reinforced cast aluminum 
bronze by modified Nano-SiC powder," Foundry, vol. 57, no. 4, pp. 330-333, 2008.

[13] J.-W. Li, M.-L. Chen, H. Gao, and Y.-H. Zhao, "Structures and properties of cast irons reinforced by trace addition of modified SiC nanopowders," Chinese Journal of Chemical Physics, vol. 20, no. 6, pp. 625-631, 2007.

[14] N. T. X. Huynh, V. van Hoang, and H. Zung, "Evolution of structure of $\mathrm{SiO}_{2}$ nanoparticles upon cooling from the melt," PMC Physics B, vol. 1, article 16, 2008.

[15] R. Carmona-Muñoz, H. M. Hdz-García, R. Muñoz-Arroyo et al., "Magnesium removal from aluminum molten alloys using silica based minerals and waste from coal-fired power (cenospheres)," Chemical Technology: An Indian Journal, vol. 8, no. 4, pp. 115-120, 2013.

[16] H. Tomokazu and S. Hidekazu, "Removal of magnesium from molten aluminium scrap by compound-separation method with shirasu," Materials Transactions, vol. 51, no. 5, pp. 838-843, 2010. 

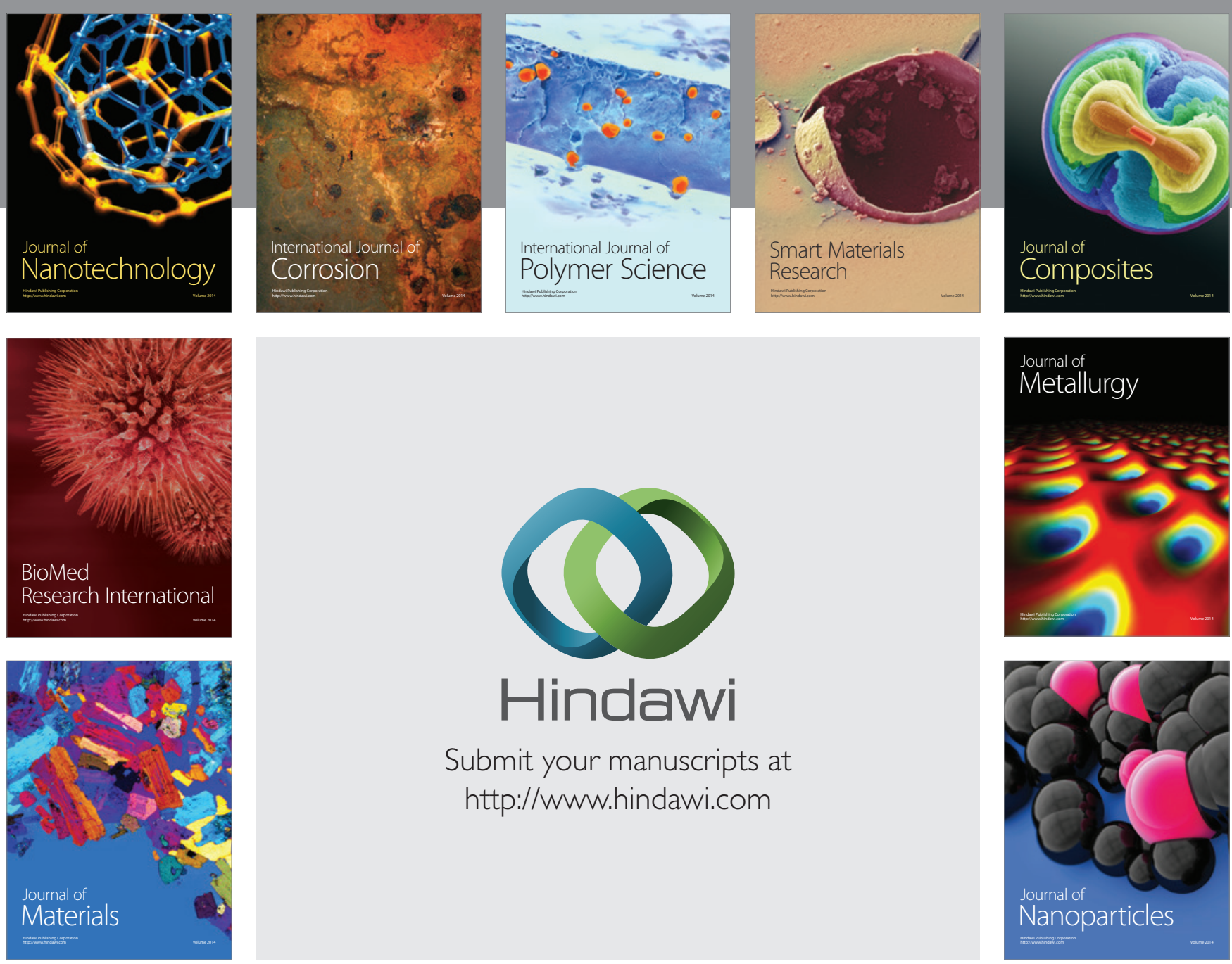

Submit your manuscripts at http://www.hindawi.com
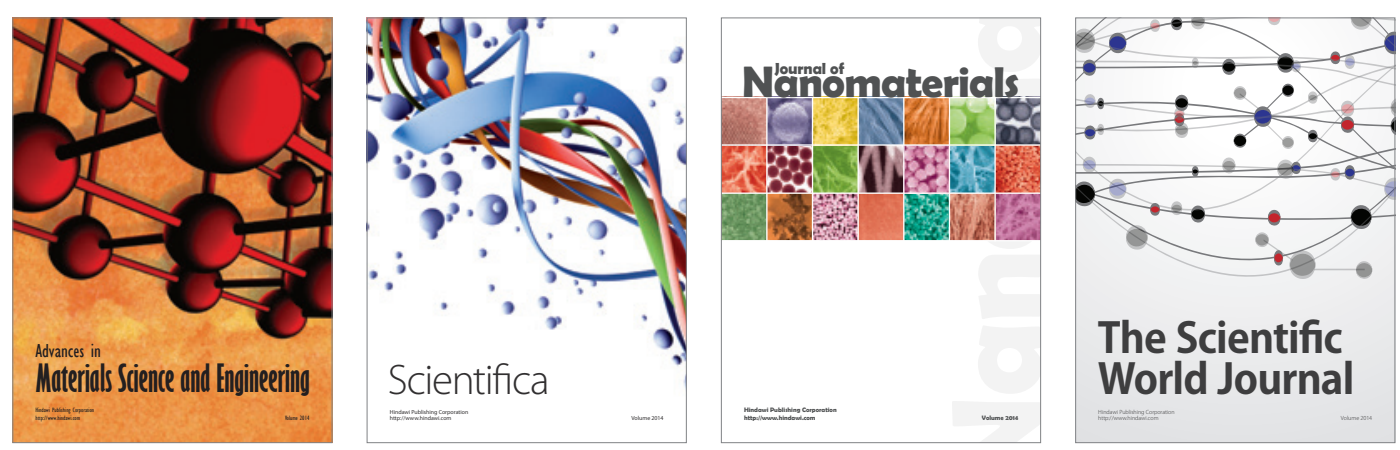

\section{The Scientific World Journal}
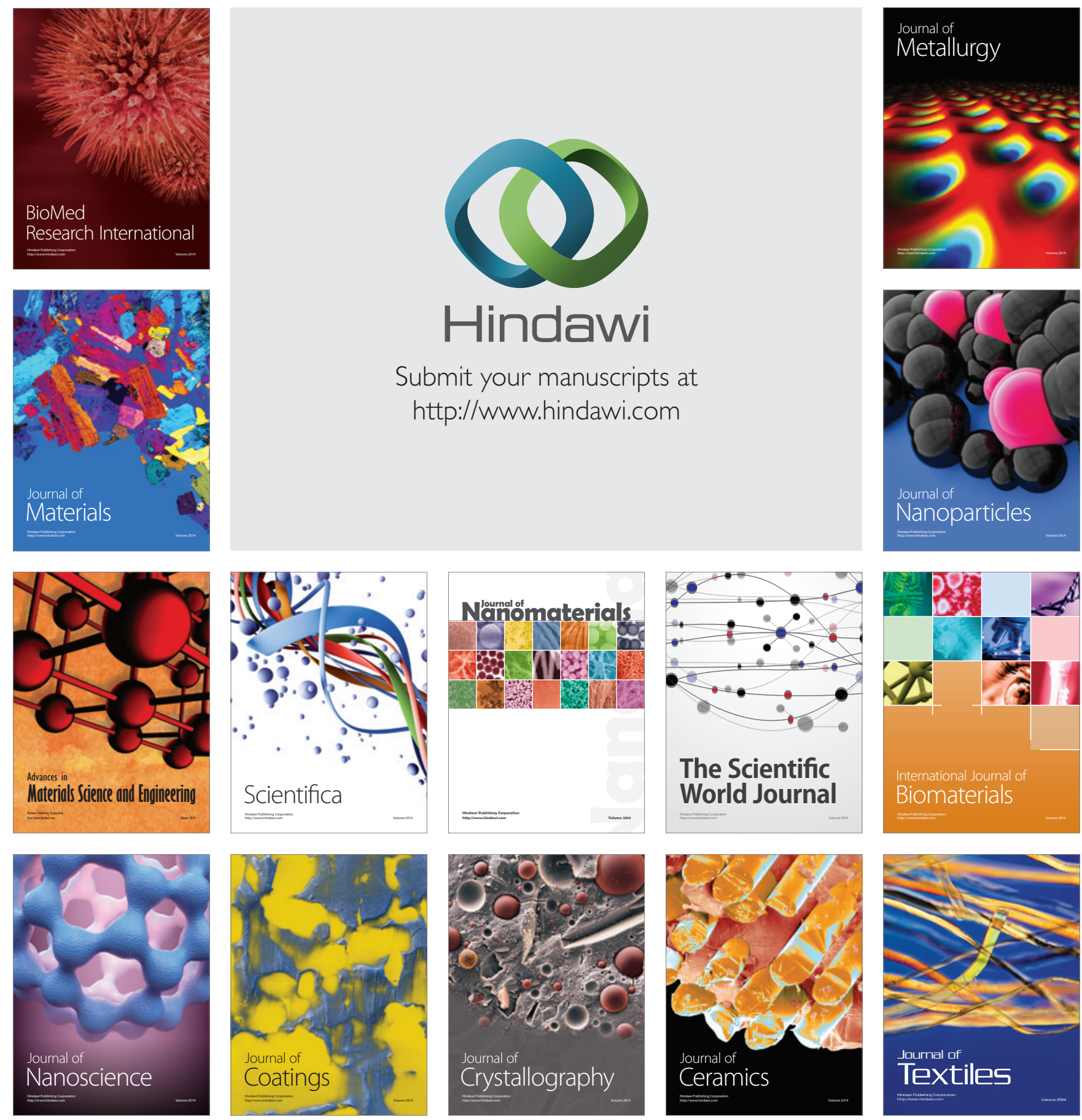